Original Article

\title{
Comparative analysis between Liquid Based Cytology and Conventional Pap Smears at B P Koirala Memorial Cancer Hospital in Bharatpur, Chitwan, Nepal
}

\author{
C B Pun, S Shrestha, R R Bhatta, G Pandey, S Uprety, S Bastakoti, I Bhattarai, Miao Zhigang ${ }^{1}$, Wu Chenpeng ${ }^{1}$
}

Department of Pathology, ${ }^{1}$ Chinese Medical Team, B P Koirala Memorial Cancer Hospital, Bharatpur, Chitwan,

\begin{abstract}
Background and Objective: Liquid based cytology was introduced at B P Koirala Memorial Cancer Hospital in Bharatpur, Chitwan, Nepal, on 29th November 2017. The objective of this study was to compare the results of conventional pap smears over six (6) months periods from 29th May 2017 to 28th November 2017 with the results of liquid based cytology smears over six (6) months periods from 29th November 2017 to 28th May 2018.

Methods: This is retrospective study. The results of conventional pap smears over 6 months and the results of liquid based cytology smears over 6 months periods were retrieved and analysed to give overall reporting profiles and compared between the two methods.

Results: The percentage of unsatisfactory smears fell $3.9 \%$ by conventional pap smears methods where as the percentage of unsatisfactory smears fell $1.2 \%$ by liquid based cytology smears. There was an increase in the number of smears reported as dyskaryosis of any grade by liquid based cytology methods.

Conclusion: The introduction of liquid based cytology led to improvements in unsatisfactory smear rates and also with significant pick up rates of dyskaryosis were maintained and improved.
\end{abstract}

\section{Introduction}

Papanicolaou stain (Pap Stain) is a multichromatic staining cytological technique developed by George Papanikolaou, the father of cytopathology. Pap staining is used to differentiate cells in smear preparations of various bodily secretions including gynaecological smears (Pap smears). Pap staining is a very reliable technique. As such, it is used for cervical cancer screening in gynecology. The entire procedure is known as conventional Pap smear.

For many years, efforts have been made to develop methods that would enhance the sensitivity and specificity of the Papanicolaou smear(also called Pap smear).

After research and development, liquid-based gynecologic specimen collection has evolved. Its proponents argue that liquid-based preparations outperform conventional smears because of improved fixation, decreased obscuring factors, and standardization of cell transfer. Proponents point out that, in direct smears, the cells are not transferred in a representative fashion and that up to $90 \%$ of the material scraped from the cervix may be discarded with the sampling device. With liquid- based collection, the sampling will be representative and operator-dependent variation will not occur since processing is controlled by the laboratory.

Liquid-based cytology is a method of preparing samples for examination in cytopathology. The sample is collecof theted, normally by a small brush, in the same way as for a conventional smear test, but rather than the smear being transferred directly to a microscope slide, the sample is deposited into a small bottle of preservative liquid. At the laboratory the liquid is treated to remove other elements such as mucus before a layer of cells is placed on a slide. The technique allows more accurate results.

SurePath (TriPath Imaging, Inc., Burlington, NC) and ThinPrep 2000 System (Cytyc Corp, Marlborough, MA) are two such systems currently approved by the U.S. Food and Drug Administration (FDA) for cervicovaginal testing. With both methods, the sample is collected in the conventional manner with one of the brush instruments but, instead of being spread onto a glass slide, it is transferred to a vial of fixative. Both methods result in a well-preserved approximate monolayer of cells with a background devoid of blood and mucus.

Correspondence

Dr. Chin Bahadur Pun, Senior Consultant Pathologist, Department of Pathology

B P Koirala Memorial Cancer Hospital, Bharatpur, Chitwan, Nepal. chinbahadurpun@hotmail.com 


\section{Methods}

This is retrospective study. The results of conventional pap smears over 6 months and the results of liquid based cytology smears over 6 months periods were retrieved and analysed to give overall reporting profiles and compared between the two methods. Total 1180 cases of conventional pap smears over six (6) months periods from $29^{\text {th }}$ May 2017 to $28^{\text {th }}$ November 2017 were analyzed. We excluded all the unsatisfactory samples for evaluation. Similarly, total 1160 cases with the results of liquid based cytology smears were included for analysis over six (6) months periods from $29^{\text {th }}$ November 2017 to $28^{\text {th }}$ May 2018. We also excluded all the unsatisfactory samples for evaluation.

\section{Results}

Age specific data and the results of the conventional Pap smear tests and the results of liquid based cytology tests are given in table I and table 2 respectively. The percentage of unsatisfactory smears fell $3.9 \%$ by conventional pap smears methods where as the percentage of unsatisfactory smears fell $1.2 \%$ by liquid based cytology smears. There was an increase in the number of smears reported as dyskaryosis of any grade by liquid based cytology methods. Dyskaryosis of any grades are included Atypical Squamous Cells of undetermined Significance (ASCUS), Atypical Squamous Cell can not exclude HSIL (ASCH), Atypical Glandular Cells, Radiation induced changes, Low Grade Squamous Intraepithelial Lesion (LSIL), High Grade Squamous Intraepithelial Lesion (HSIL) and suspicious for squamous cells carcinoma. The cases were youngest 18 years of age to oldest 86 years of age.

\section{Pap Smears Cytology (Table 1)}

\begin{tabular}{|l|l|l|l|l|}
\hline \multicolumn{1}{|c|}{ Age } & $\begin{array}{c}\text { Normal/In- } \\
\text { flammatory } \\
\mathbf{n}(\%)\end{array}$ & $\begin{array}{c}\text { Cell } \\
\text { atypias } \\
\mathbf{n}(\%)\end{array}$ & \multicolumn{1}{|c|}{$\begin{array}{c}\text { Total } \\
\mathbf{n}(\%)\end{array}$} & $\begin{array}{c}\text { Unsatisfactory } \\
\text { smears } \mathbf{n}(\%)\end{array}$ \\
\hline$<20$ years & $3(0.25)$ & - & $3(0.25)$ & - \\
\hline $21-30$ years & $186(15.7)$ & $5(0.42)$ & $191(16.1)$ & $5(0.42)$ \\
\hline $31-40$ years & $393(33.3)$ & $6(0.5)$ & $399(33.8)$ & $14(1.18)$ \\
\hline $41-50$ years & $326(27.6)$ & $11(0.9)$ & $337(28.55)$ & $22(1.86)$ \\
\hline $51-60$ years & $166(14.06)$ & $5(0.42)$ & $171(14.4)$ & $4(0.33)$ \\
\hline $61-70$ years & $67(5.6)$ & $3(0.25)$ & $70(5.9)$ & $2(0.16)$ \\
\hline $71-80$ years & $6(0.5)$ & $2(0.16)$ & $8(0.67)$ & - \\
\hline$>80$ years & $1(0.08)$ & - & $1(0.08)$ & - \\
\hline & $1148(97.28)$ & $32(2.71)$ & $1180(100)$ & $47(3.98)$ \\
\hline
\end{tabular}

Liquid Based Cytology (Table 2)

\begin{tabular}{|l|l|l|l|l|}
\hline \multicolumn{1}{|c|}{ Age } & $\begin{array}{c}\text { Normal/In- } \\
\text { flammatory } \\
\mathbf{n}(\mathbf{\%})\end{array}$ & $\begin{array}{c}\text { Cell } \\
\text { atypias } \\
\mathbf{n}(\%)\end{array}$ & \multicolumn{1}{|c|}{$\begin{array}{c}\text { Total } \\
\mathbf{n}(\%)\end{array}$} & $\begin{array}{c}\text { Unsatisfacto- } \\
\text { ry smears } \\
\mathbf{n}(\%)\end{array}$ \\
\hline$<20$ years & $5(0.43)$ & - & $5(0.43)$ & - \\
\hline $21-30$ years & $179(15.4)$ & $4(0.34)$ & $183(15.7)$ & $1(0.08)$ \\
\hline $31-40$ years & $392(33.79)$ & $11(0.94)$ & $403(34.7)$ & $4(0.34)$ \\
\hline $41-50$ years & $334(28.7)$ & $18(105)$ & $352(30.34)$ & $7(0.60)$ \\
\hline $51-60$ years & $156(13.44)$ & $5(0.43)$ & $161(13.8)$ & $2(0.172)$ \\
\hline $61-70$ years & $41(3.53)$ & $4(0.34)$ & $45(3.8)$ & - \\
\hline $71-80$ years & $6(0.51)$ & $3(0.25)$ & $9(0.77)$ & - \\
\hline$>80$ years & $2(0.172)$ & - & $2(0.172)$ & - \\
\hline & $1115(96.12)$ & $45(3.87)$ & $1160(100)$ & $14(1.2)$ \\
\hline
\end{tabular}

\section{Discussion}

According to the Jyotsna Sharma et al some of the major advantages of LBC noted in their study were lesser screening time, cleaner background and the better spread of cellular elements. An almost equal number of unsatisfactory smears were encountered in conventional Pap (8\%) and LBC (7\%) in their study. Similar study by David et al showed no significant difference in the rate of inadequate/unsatisfactory smears between LBC and Conventional Pap smears. Albertus G. Siebers et al did a randomized controlled trial and indicated that liquid-based cytology does not perform better than conventional Pap tests in terms of relative sensitivity and for detection of cervical cancer precursors.

A study by Singh VB et al showed LBC technique leads to significant reduction of unsatisfactory rate. LBC samples offered better clarity, uniform spread of smears, less time for screening and better handling of haemorrhagic and inflammatory samples. LBC had equivalent sensitivity and specificity to conventional Pap smears.

According to the study by Abhinav Walia and Ujwala Maheshwari, women screened with an LBC sample had significantly decreased detection rates of inadequate smears and increased detection of low grade squamous intraepithelial lesion/ atypical cytology. Which will significantly improve early detection and treatment of cervical lesions.

Uma Singh et al concluded the results showing that the LBC performed better than the conventional method of cytology to detect recurrence of squamous cell carcinoma. Its sensitivity, specificity as well as accuracy were much higher than the conventional method. LBC can be better method of cytological follow up of post-treated patients of cancer cervix apart from a reduction in adequate smears. Beerman $\mathrm{H}$ et al did a population- based cervical cancer screening programme, which confirmed previous 
institution based reports of decreased numbers of unsatisfactory samples based on liquid-based cytology and showed an increased sensitivity for the detection of cytological abnormalities that was validated by subsequent histological investigation.

According to the randomised controlled trial by Guglielmo Ronco et al with Liquid based cytology the unsatisfactory rate was reduced in comparison to the coventional Pap smear. The average primary screening and rapid rescreening time of each slide were reduced from 8 minutes to 4 minutes and from 2 minutes to less than 1 minute, respectively in liquid based cytology.

Sueli Aparecida Batista Stabile et al did comparative study of the results from coventional cervico-vaginal oncotic cytology and liquid -based cytology and concluded that Liquid-based cytology had a better performance to diagnose atypical cells and the cytohistological concordance was higher than in the conventional cytology. PE Castle et al did two randomised clinical trials and concluded that the proportion of unsatisfactory samples was lower in liquid-based cytology compared with conventional cytology.

ARW Williams compared liquid-based cytology and conventional smears over two 12-month periods and concluded that introduction of liquid based cytology led to improvements in unsatisfactory smear rates, with significant benefits to colposcopic referrals and laboratory turnaround times. Pick-up rates of dyskaryosis were maintained, and the positive predictive value of a dyskaryotic smear report was improved.

We did a similar comparative study to compare the results of liquid based cytology with the results of conventional Pap smear cytology. According to our study the introduction of liquid based cytology led to improvements in unsatisfactory smear rates and also with significant pick up rates of dyskaryosis were maintained and improved.

Liquid based cytology was developed to improve the diagnostic reliability of Pap smears. Conventional Pap smears can have false-negative and false-positive results because of inadequate sampling and slide preparation, and errors in laboratory detection and interpretation. However, liquid based cytology rinses cervical cells in preservatives so that blood and other potentially obscuring material can be separated.

\section{Conclusion}

Although authors have some discrepancy but majority are in favour of liquid based cytology which will enhance the diagnostic reliability of conventional Pap smears. The introduction of liquid based cytology led to improvements in unsatisfactory smear rates and also with significant pick up rates of dyskaryosis were maintained and improved.

\section{References:}

1. Jyotsna Sharma, Pampa Ch Toi, Neelaiah Siddaraju, Malliga Sundareshan, Syed Habeebullah, et al. A comparative analysis of conventional and SurePath liquid-based cervicovaginal cytology: A study of 140 cases. J Cytol. 2016 Apr-Jun;33(2):80-84.

2. Albertus G. Siebers, Paul J. J. M. Klinkhamer, Johanna M, M. Grefte, et al. Comparison of liquid-based cytology with conventional cytology for detection of cervical cancer precursors: A randomized cotrolled trial. JAMA. 2009;302(16):1757-1764.

3. Singh VB, Gupta N, Nijhawan R, Srinivasan R, Suri $\mathrm{V}$, Rajwanshi A, et al. Liquid-based cytology versus conventional cytology for evaluation of cervical Pap smears: experience from the first 1000 split samples. Indian J Pathol Microbiol. 2015 Jan-Mar;58 (1): 17-21.

4. Abhinav Walia, Ujwala Maheshwari. Comparative study of conventional Pap smear versus manual liquid based cytology in screening of cervical cancer. Scientific Tracks Abstracts-workshop: J Clin Exp Pathol. DOI: 10.4172/2161-068.SI.016.

5. Uma Singh, Anjum, Sabuhi Qureshi, Neha Negi, et al. Comparative study between liquid-based cytology \& conventional Pap smear for cytological follow up of treated patients of cancer cervix. Indian J Med Res. 2018 Mar; 147 (3): 263-267.

6. Beerman H, Van Dorst EB, Kuenen-Boumeester V, Hogendoorn PC, et al. Superior performance of liquid-based versus conventional cytology in a population-based cervical cancer screening program. Gynecol Oncol. 2009 Mar;112 (3): 572-6.

7. Guglielmo Ronco, Jack Cuzick, Paola Pierotti, Maria Paola Cariaggi, et al. Accuracy of liquid based versus conventional cytology: overall results of new technologies for cervical cancer screening: randomiseed controlled trial. BMJ. 2007 Jul 7; 335 (7609): 28.

8. Sueli Aparecida Batista Stabile, Dilson Henrique Ramos Evangelista, et al. Comparative study of the results from conventional cervico-vaginal oncotic cytology and liquid-based cytology. Einstein ( Sao Paulo) vol.10 no. 4 Sao Paulo Oct./Dec. 2012.

9. A.R.W.Williams. Liquid-based cytology and conventional smears compared over two 12-month periods. Citing Literature. 2006 April;17 (2): 82-85. 